Clinical Image

\section{Vaginal and endometrial metastasis of primary cutaneous malignant melanoma}

\author{
Maria Boia Martins, Francisca Morgado, Nuno Oliveira and \\ Filomena Ramos
}

Portugal

\section{More Information}

*Address for Correspondence: Maria Boia Martins, Portugal, Tel: + 351969999669 ; Email: mariaboiamartins@gmail.com; 18310@chbv.min-saude.pt

Submitted: 14 September 2020 Approved: 16 September 2020 Published: 16 September 2020

How to cite this article: Martins MB, Morgado F, Oliveira N, Ramos F. Vaginal and endometrial metastasis of primary cutaneous malignant melanoma. Clin J Obstet Gynecol. 2020; 3: 120-120.

DOI: 10.29328/journal.cjog.1001062 ORCiD: orcid.org/0000-0002-4760-6064

Copyright: (c) 2020 Martins MB, et al. This is an open access article distributed under the Creative Commons Attribution License, which permits unrestricted use, distribution, and reproduction in any medium, provided the original work is properly cited.

\section{(A) Check for updates \\ - $)$ OPEnaccess}

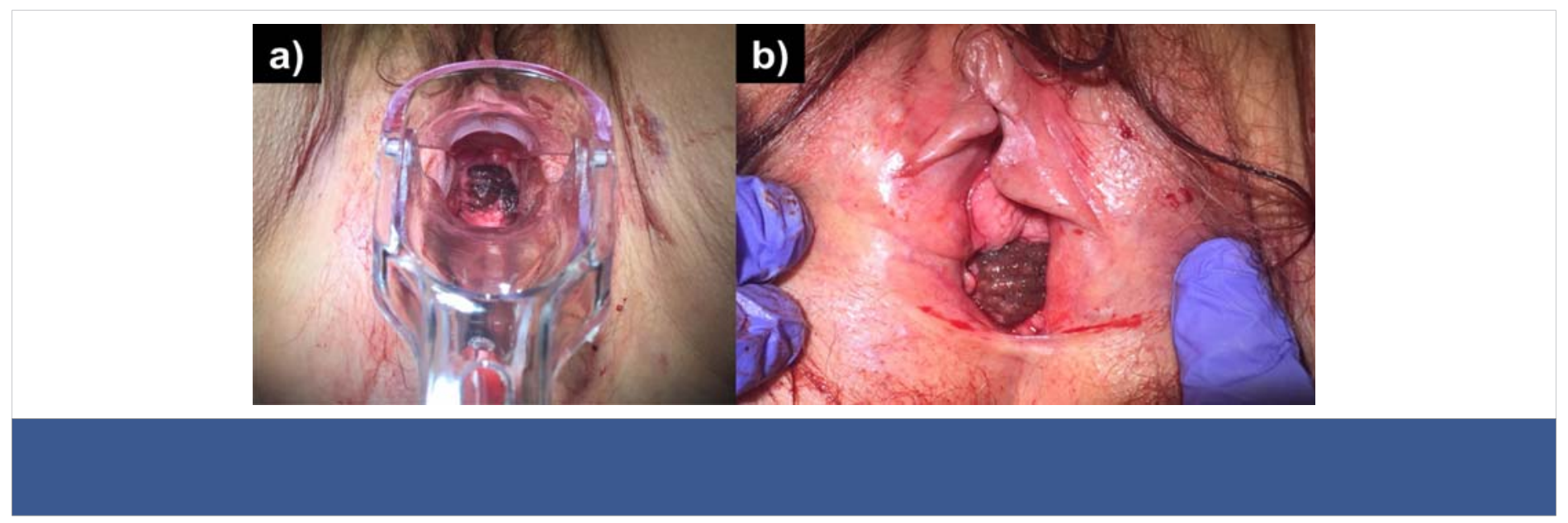

